\title{
Inaudible Visitors: Theories of sound reproduction in the studio practice of Pierre Schaeffer
}

\author{
REUBEN DE LAUTOUR \\ Program in Sonic Arts, Center for Advanced Studies in Music (MIAM), Istanbul Technical University, Macka Kampusu, Istanbul 34357, Turkey \\ Email: lautour@itu.edu.tr
}

\begin{abstract}
In this article I explore the relationship of theories of sound reproduction formulated in the decades between the two world wars with the studio practice of Pierre Schaeffer. I argue that the 1920s-1930s was a period of significance for sound-based arts, and compare it to analogous defining moments in cinema and art photography. After examining the legacy of this period, I turn to one specific moment from Schaeffer's early studio experiments with musique concrète in April 1948, showing how the theories of sound reproduction formed in the earlier time period informed practical decisions in Schaeffer's working methods at a critical time when his ideas about the sound object were forming. Schaeffer's studio practice and, to an extent, his theories of listening thus carry traces of this prior sonic culture. Considering the decisive influence of Schaeffer's writings and teaching on later generations and developments in electroacoustic music, I speculate on the proliferation of these ideas beyond Schaeffer's immediate circle, focusing in particular on soundscape composition. The title of this article is a reference to James Lastra's 'invisible auditor', a term he coined to characterise the approach to sound reproduction discussed in this article (Lastra 2000: 159).
\end{abstract}

\section{INTRODUCTION}

The profile today of art forms that incorporate sound reproduction technologies is very different from those associated with visual media; cinema and art photography are culturally visible in ways that the phonographic arts are not. Of the various devices for capturing sounds and images that appeared during the nineteenth century, cameras have been absorbed into singular, universally identifiable artistic practices, while in contrast, sound reproduction has become intertwined with a range of diverse forms - electroacoustic music, sound art, sound design, recorded music and field recording to name only a few - of which none seem dominant or representative in quite the same way. Perhaps speaking to this situation, Douglas Kahn once lamented: 'Art photography is commonplace, but an art phonography? When compared to the photographic arts, the phonographic arts are retarded' (Kahn 1990: 301). While Kahn's dismissal of the many sound-based arts that have appeared since the invention of the phonograph is questionable, certainly there is no unique, easily identifiable artistic culture of phonographic art equivalent to art photography or cinema.

In light of this it is perhaps no surprise that composers of electroacoustic music frequently resort to analogies with visual media when they feel their work transcends traditional genre descriptions. For example, sometime during the 1970s the term 'Cinema for the Ear', which has been attributed variously to Michel Chion (Landy 2007: 89), Francois Bayle (Kane 2014: 51) and, latterly, Robert Normandeau, arose to describe a narrative style of tape composition distinct from the more abstract ethos of musique concrète (Ogborn 2008). In the previous decade, Luc Ferrari referred to his tape compositions as 'electroacoustic nature photographs' (Emmerson 2007: 7), perhaps wishing to emphasise the visual as a response to the predominance of acousmatic approaches to electroacoustic music in the 1950s. More recently Paul Lansky described using the computer as an 'aural camera' (Willie 1993: 4). Sometimes composers and musicians turn to such analogies in an attempt to help audiences come to grips with a sound world they think will be unfamiliar, as when Jimi Hendrix described the evocative electronic textures of the track ...And the Gods Made Love as 'sound painting' (Worby 2000: 151) after expressing the concern that his fans would probably not like it.

Photographic or cinematic analogies are intuitive and useful in part because, from a historical perspective, sound reproduction has much in common with photography and cinema. Devices for capturing still or moving images and sound were invented within a few decades of each other, and the kinetograph (one of the first systems for producing moving images) and the phonograph even share an inventor, Thomas Edison. Innovators in each medium also faced similar types of scepticism from within the ranks of related, pre-existing artistic cultures: photographers struggled with painters and illustrators, filmmakers fought with scenarists and playwrights, and sound engineers entered into complex and delicate negotiations with musicians. 
But why are these analogies necessary? Assuming (as most composers probably would) that Douglas Kahn is wrong about the phonographic arts and that electroacoustic music is indeed a bona fide mode of artistic expression with its roots in phonographic technologies, what is lacking in the theory or discourse of electroacoustic music such that so many composers find it difficult to ascribe a descriptive moniker to their artistic practice without resorting to art photography and cinema?

In this article I argue that theories of sound reproduction formulated during collaborative research projects between electrical engineers and classical musicians in the $1920 \mathrm{~s}-1930 \mathrm{~s}$, which I refer to as 'fidelity theories', became embedded in the studio practice of Pierre Schaeffer. As I will show, these theories were geared to a specific musical culture and are not well suited to the demands of musique concrète (or indeed any other form of electroacoustic music). Schaeffer's influence on subsequent discourse in electroacoustic music is well documented, so it seems likely that fidelity theories may also have found their way via Schaeffer into other strands of postSchaefferian discourse. It is beyond the scope of this article to examine the influence of these theories on post-Schaefferian theory and practice generally, so I will limit my discussion to musique concrète and soundscape composition.

Musique concrète and soundscape are useful points of focus because these genres have produced large, coherent bodies of theoretical literature. Additionally, soundscape composition is one of a number of postSchaefferian trends that explicitly link electroacoustic sounds to real-world causes, placing soundscape and concrète at opposing poles of the 'source identification' spectrum (Emmerson 2007: 5-9). If a link exists between these two genres, my reasoning goes, then there is a good chance that the argument applies to a degree in many other genres that exist along this spectrum. For the purposes of this article, musique concrète is work produced by composers at the Groupe de Recherche Musicale (GRM, or one of its various incarnations) in Paris during the years when Schaeffer was in a leadership role, and soundscape composition is understood as a body of work produced by those involved in the formation of the World Soundscape Project in Vancouver in the early 1970s. I should also note that the discussion below is limited to acousmatic music, that is, fixed-media or 'tape' composition composed for playback and diffusion through loudspeakers. Other forms of electroacoustic music such as live electronics, mixed-electroacoustics (music involving live instrumental performance) and multimedia composition are not considered at the present time.

In order to create a link between theories of sound reproduction and Schaeffer's studio practice, I will make a brief detour through the early years of cinema, art photography and electrical recording. Specifically, I focus on periods of intense debate that occurred in the decades immediately following the appearance of the daguerreotype, the kinetograph and the phonograph, in which theorists and practitioners argued over whether or not these media offered the possibility of unique artistic forms. I refer to these periods of debate as 'Is it art?' moments.

\section{THE 'IS IT ART?' MOMENTS IN CINEMA, ART PHOTOGRAPHY AND SOUND REPRODUCTION}

At key moments, critics and practitioners engaged in early photography and moving pictures debated the question of whether each medium could sustain modes of production that might be categorised or understood as art in a traditional sense. In the case of cinema and art photography, they worked together with surprising cohesion and clarity of purpose. There was a clear question at stake - 'Can photography/cinema be art?' followed by a heated, decades-long debate. An important feature of each of these debates was the interaction with a prior artistic practice. Sceptics and partisans both compared photography to painting, and moving pictures to theatre. The first filmmakers and photographers acknowledged and responded to these comparisons with specific creative strategies or techniques in their photographs and movies.

Public discussions about the relative merits of photography and painting began more or less as soon as the first photographs were taken, and intensified during the 1850s when public figures such as the French poet Charles Baudelaire attacked photographer's aspirations to be artists (Van Gelder and Westgeest 2011: 14-16). In response, the first generation of art photographers appropriated subjects, themes and techniques from existing schools of painting, mimicking chiaroscuro and the textures of various materials used by painters (Sandler 2002: 57). They also adopted painting's distinction between landscape and portrait frame dimensions, and by the turn of the century, photographs were framed and hung on walls like paintings (Giblett 2012: 15; Sandler 2002: 59-60). By this time, exhibitions of art photography were commonplace in European galleries and photography had been generally accepted as one of the fine arts (Sandler 2002: 64).

Cinema's 'Is it art?' debate took place during the first couple of decades of the twentieth century. Early histories of cinema describe a process of clear and seemingly inevitable progress towards artistic status (Bordwell 1999: 12-45). Filmmakers encountered comparisons with theatre just as photographers had with painting, but the relationship of moving pictures to theatre was slightly different. The first narrative films were criticised as photographed theatre 
(Bordwell 1999: 26; Carroll 2008: 10; Abel 1988: 19), so unlike photographers, who had attempted to demonstrate that photography was 'as good as' painting, early filmmakers had to show that cinema was different from theatre (Abel 1988: 20). Rollin Summers argued that the absence of spoken dialogue in silent film had forced cinema to develop a new language of visual representation (Bordwell 1999: 29-30), while other critics and directors emphasised technical possibilities they considered uniquely filmic, such as editing and cinematography (Carroll 2008: 42).

The 'Is it art?' debates in cinema and art photography, though reductive and problematic in many regards, fulfilled an important discursive function. Film historian David Bordwell identifies what he calls a 'standard version' of film history that told a story beginning with technical innovations in France and the first masterworks in the United States in the years before the First World War, up to around 1930 when there was a 'remarkable consensus' about cinema's triumphant fulfilment of its potential as a uniquely modern art form (Bordwell 1999: 12-45). 'Emergence of art' narratives like this are appealing because the histories of art from which they borrow are also histories of civilisations (Janson and Janson 2003); the 'Is it art?' debates thus allowed cinema and art photography to be seen as 'developing' along with reassuring patterns of high-culture production, criticism, spectatorship and exhibition.

As Bordwell notes, his 'standard version' of film history frequently oversimplifies, exaggerates, or ignores certain aspects of early cinema, and according to Mary Warner Marien, 'few painters saw photography as a threat' (Marien 2006: 28), suggesting that the 'photography versus painting' debate was guilty of similar exaggerations and distortions. Nevertheless artistic progress narratives like the 'standard version' or 'photography versus painting' had the positive effect (for filmmakers and photographers) of sanctioning certain creative practices, and it is probably not coincidental that specific professional roles clarified around the same time (Monaco 2010: 6-17). Equally important was a group of professional critics who mounted persuasive defences of cinema and art photography (Carroll 2008: 7-34).

The closest thing to a phonographic 'Is it art?' moment was a debate over the artistic possibilities of sound reproduction that took place between various parties involved or interested in the recording and reproduction of classical music during the years between the two world wars, which some contemporary writers referred to as phonographic 'romanticism versus realism' (Symes 2004: 67). The Bell Telephone Laboratories invested in large research projects with the aim of developing the electrical reproduction of music (McGinn 1983), and the invention of first-generation electronic instruments such as the Theremin, Ondes Martenot and the Trautonium contributed to a thirst for experimentation. Composers Paul Hindemith, Ernst Toch and Ottorino Resphighi sought novel uses for the phonograph and incorporated mechanical themes in their creative output (Randel 2003: 289; Symes 2004: 50-2).

There were several critical differences in the phonographic debates. First, unlike cinema and art photography, phonography lacked a class of specialist critics. Debates about phonograph aesthetics took place in the relatively limited discursive domain of articles or editorials in scientific journals and in news reports, reviews, correspondence and various other musings in the pages of audiophile magazines such as The Gramophone and High Fidelity (Symes 2004: 66).

Second, whereas filmmakers and photographers vigorously staked their territory as artists, those primarily responsible for guiding theory and practice in sound reproduction - 'sound engineers', as they began to call themselves during the 1920 s - did the exact opposite. These scientists saw their primary concern as bringing scientific rigor and standardisation to the previously empirical, rule-of-thumb practice of mechanical sound recording (Burns 1999: 92). Unlike their predecessor Thomas Edison, who was very much involved in musical decisions (Harvith and Harvith 1987: 3-6), sound engineers were less comfortable discussing aesthetic matters (Morton 2000: 26), with prominent scientists such as Joseph Maxfield of the Bell Laboratories encouraging a division of labour where sound engineers restricted themselves to 'technical' concerns and left all artistic decisions in the hands of musicians (Maxfield 1932: 122).

The artistic deference shown towards musicians by the first-generation sound engineers is perhaps understandable given the high social status of classical musicians in the 1920s (Morton 2000: 24-6), and the intimidating presence of musical celebrities such as Leopold Stokowski in collaborative research projects (McGinn 1983). Combined with the loyal buying habits of classical music listeners in the face of a radio-inflicted slump in the recording industry during the 1920s, this gave classical music culture an economically disproportionate influence on the development of the phonograph (Morton 2000: 33-47).

The phonographic 'Is it art?' moment thus proved less conclusive, and the status of recorded music as a kind of representational art in its own right has been argued over ever since (Symes 2004: 84-7). Strangely, the pages of The Gramophone magazine and scientific articles contain scant reference to the artistic endeavours of experimentalists such as Toch and Hindemith (whose work I discuss below), with the bulk of discourse given over to the predominant commercial use of the phonograph as a medium of recorded music. What then is the relevance of this body of theory to more recent forms of electroacoustic music such as musique concrète or soundscape? 


\section{TRACING THE INFLUENCE OF THE 'IS IT ART?' MOMENTS IN ELECTROACOUSTIC MUSIC THEORY}

Several factors amplified the influence of phonography's 'Is it art?' moment. A huge proportion of the scientific discourse on the topic of sound reproduction came from a small group of industrial research institutions closely integrated with the Bell Telephone Laboratories (hereafter BTL) in the north-eastern United States. BTL was a powerful organisation with a big stake in the phonograph industry, and the ability of scientists and executives to set research agendas afforded them considerable opportunity to shape scientific thought and influence practice in the sphere of sound reproduction (Lastra 2000: 163).

The involvement of the scientific community in recording discourse brings to mind Bruno Latour's ideas about the power of academic literature to isolate the lay reader (Latour 1987: 21-44). As a scientific debate unfolds, Latour argues, statements and citations are layered on one another in a branching web of increasing scholastic complexity, with the effect of marginalising readers without specialist knowledge or adequate time to follow every branch of the discussion. Faced with a barrage of literature, dissenting voices are either forced to reckon with the evidence or surrender to prevailing scientific thought. The correspondence pages of The Gramophone magazine in the 1930 s are filled with such vanquished dissenting voices. A letter penned by Cedric Wallis, an avowed 'phonograph romantic', mourned the passing of mechanical phonography: 'With the advent of the electrical process of recording ... the Romantics were drummed off the battlefield' (Wallis 1936).

The emotional nature of texts such as these suggests that there was far more at stake than a simple competition of recording formats. In fact, the 'romanticism versus realism' debate served to entrench a particular musical culture as a reference point for evolving theories of sound reproduction. For example, Oliver Read and Walter Welch's monumental defence of mechanical phonography (Read and Welch 1959: 237-54) contained harsh critiques of popular music disguised as technical disquisitions, as in the following passage where their distaste for crooning and light music is shrouded in an attack on recording 'standards':

What would Mr. Robinson or Mr. Kellog say today about the use of echo-chambers in recordings, which are cut in or out like the grand swell of the pipe organ; or of the layering of one recording over another recording repeatedly to simulate echo and orchestral effects with but one voice and/or instrument? What would these gentlemen say about Montovani [sic]? Suppose the instrument to begin with is an already electrically amplified guitar and the alleged singer is crooning softly into the microphone - perhaps using a throat contact mike - just what is reality? (Read and Welch 1959: 253)
Texts like these demonstrate the way in which cultural preferences entered incognito into discussions of sound reproduction via technical debates. Jonathan Sterne has shown convincingly how theories of sound fidelity are expressive of social relationships as much as technical ones, and notes that Read and Welch's preferences are aesthetic rather than technical (Sterne 2003: 277-8). Since the musical culture that these critics and scientists most closely identified with was European art music of the common practice era, their models of sound reproduction and ensuing 'technical' innovations were explicitly geared to this particular musical culture. As I discuss below, composers and theorists working in the field of electroacoustic music have inherited these theories along with all their associated musical and cultural baggage, creating unnecessary problems and silencing other potentially more interesting lines of inquiry.

The sheer cultural loudness of the 'Is it art?' moment ensured that any subsequent artistic or commercial development involving music and sound reproduction would necessarily bear its imprint. There are obvious parallels between the notion in recording discourse of referentiality - the extent to which a recording can or should be heard as a sonic facsimile of a unique musical performance - and the issue of source recognition in electroacoustic music theory. Since the 1920s, theories of sound reproduction have returned 'obsessively' to the issue of identity between the recording and the recorded (Lastra 2000: 124). Similarly, source recognition is for many historians a defining issue in Schaefferian and post-Schaefferian electroacoustic music theory (Demers 2010: 22; Emmerson 2007: 5). The irony in the case of recording discourse is that referentiality, or source identification of a musical performance (to put it in the terms of Schaefferian discourse), relied on constructing an original for the purpose of recording. Recent critiques of this approach emphasise the dependence of the original on the copy, arguing, to paraphrase James Lastra's elegant explanation, that ideality (the notion of a unique original sound event) depends on repetition (Lastra 2000: 150-3), or as Jonathan Sterne puts it, that originals cannot exist without copies (Sterne 2003: 219).

Both musique concrète and soundscape, in terms of practice, also rely on notional 'original' sound events that in practice only exist in relation to their recorded form. In Pierre Schaeffer's studio, sound events were 'performed' on physical objects specifically for the purpose of being recorded; after 1948, Schaeffer himself never heard the unmediated versions of these recordings (see following discussion). In the case of soundscape music, the ideological framework of acoustic ecology guided the first recordists and composers in choosing and recording specific sounds that they associated with a particular geographical location. Even though one might argue that these sounds already existed prior to the recording in a way that Schaeffer's sound objects did not, 
nevertheless the classification and attribution of certain characteristics to certain sounds - for example, as a 'keynote' or 'soundmark' -required the listener to impose a preferential hierarchy on sound events in that environment (Schafer 1977: 10). Composers and recordists of the World Soundscape Project (hereafter WSP) also used close microphone technique in the field in order to be able to isolate and have greater control over the processing of particular sound events over others during studio montage and mixing (Truax 2002: 10).

Moreover, in all three cases, meta-textual elements accompanied the presentation of the sound reproduction/composition, helping the listener to associate the sounds with a real or phantom 'cause'. In recording discourse, radio or phonograph enthusiasts had detailed programme information about the performers and works that were presented; in soundscape composition, recordings sometimes included cartographical guides and descriptions of what to listen to, as in the Vancouver Soundscape album (1973).

Schaeffer's use of meta-textual clues is less consistent yet all the more significant given his commitment to breaking the chain of signification between a sound and its cause. In his early oeuvre, the titles of some of his works made the source explicit such as the Étude aux casseroles and the Étude aux chemins de fer. Perhaps more than any of his colleagues at the Paris studio, he frequently used the sounds of musical instruments as source material, often without bothering to disguise them with studio manipulations ; for example, in the Diaspon Concerto or the improvisations provided by Pierre Boulez that made up the sonic material for the Etude Violette and the Etude Noire. Even in the works of the late 1950s, where Scaheffer took a much stricter approach to preventing source recognition (Kane 2014: 120), the sound sources are often identifiable; for example, the violin sounds in Étude aux Objets where playing techniques such as sul ponticello and glissando that are specific to stringed instruments emphasise the 'violin-ness' of certain sounds. In any case, as Michel Chion notes, the insistence on blocking source recognition arguably has the effect of piquing the listener's curiosity about potential causes (Chion 2012: 52); so even (or perhaps especially) in the absence of a specific cause, listening is still framed by causality.

Theories of sound reproduction that rely on identification of original sound events with associated recordings - 'fidelity theories' - have much in common with the source identification discourse in Schaefferian and postSchaefferian theory, and I believe that there is an important point of contact between the two. I argue in the following section that through his training and vocation as a broadcasting engineer immersed in the culture of sound reproduction created at BTL, Pierre Schaeffer bridged two significant moments in the history of the phonographic arts: the 'Is it art?' debate described above, and the period where he formulated his theory of the sound object.

\section{FIDELITY THEORIES AND PIERRE SCHAEFFER'S STUDIO PRACTICE}

In his book Sound Unseen, Brian Kane describes the emergence of Schaeffer's theory of the sound object by examining the earliest entries in Schaeffer's diaries of his activities at the studios of Radiodiffusion Française (Kane 2014: 15-17). These entries are significant for Kane because they describe the messy and frustrating experiments Scaheffer undertook while arriving at a conception of musique concrète and the sound object that is fairly close to what appears in his monumental treatise the Traite des Objets Musicaux (hereafter TOM), published almost two decades later. Kane traces a series of subtle shifts in the way Schaeffer uses the term 'sound object'; it appears first as merely 'object' to describe a sound-producing physical object, then 'sound object' to describe these objects when heard acousmatically (through loudspeakers). Finally by May 1948, Schaeffer defines the 'sound object' as a perceptual phenomenon, the 'in-itself-ness' of sound independent of its cause or physical origin (Schaeffer 2012: 13-14).

Since the phenomenological framework that is so closely identified with Schaeffer's legacy came along much later (Kane 2014: 18), this presents scholars of Schaeffer with the problem expressed in his enigmatic statement 'for years, we have been doing phenomenology without realising it' (Chion 1983: [32]). ${ }^{1}$ As Kane points out, if Schaeffer's phenomenology was 'explicitly retrospective' (Kane 2014: 19), how does his early studio practice relate to his theoretical output?

Kane responds to this question with a subtle analysis of the flavour of phenomenology Schaeffer invokes in the TOM, revealing contradictions between his notion of the sound object and acousmatic listening as a practice (Kane 2014: 19-41). This period has also come under scrutiny from John Dack, who traced the influence of symbolist literature on Schaeffer's early radiophonic art (Dack 1994). I wish to examine this moment with slightly different questions in mind. My inquiry is focused less on Schaeffer's theory of sound objects or his ideas about listening, and more on how he behaved as a listener and composer at work in his studio.

The diary entries marked 17-18 April 1948 describe a significant turning point in Schaeffer's studio practice. On the 17th Schaeffer describes trying to construct a fascinating hybrid instrument/sound sculpture: 'a vibrating metal strip that you can bring into contact with

${ }^{1}$ Quotations from Schaeffer's TOM are sourced from Christine North and John Dack's English translation of Michel Chion's 'Guide des objets sonores'; the bracketed numbers refer to the corresponding section in both the original French and the English translation. 
any object. It then produces a "knocking noise." Dampen the vibration of a crystal glass, a bell, with your fingernail, or cardboard, or a piece of metal, and you mingle noise, sound, a rhythm' (Schaeffer 2012: 6). Somewhat inexplicably, he concludes 'the results are profoundly monotonous ... I'm giving up on music.' The next day's entry sees a sudden decision to relocate his sphere of activity to the 'sound booth' (what we would now call the control room) rather than the 'recording booth':

You can't be in two places at once. I must choose between the Studio and the sound booth. This is where I finally took refuge. A window protects me from the Studio. I am among the turntables, the mixer, the potentiometers. I feel vaguely reassured. I operate through intermediaries. I no longer manipulate sound objects myself. I listen to their effects through the microphone. Which amounts to burying my head in the sand, since the microphone only gives the raw sound with some secondary effects and qualitatively adds nothing. (Schaeffer 2012: 6-7)

From this point on, Schaeffer did not fabricate or play sound-producing instruments himself; he listened, interpreted and manipulated sound objects from the relative comfort of the sound booth. The feeling of security he describes from being 'protected' by the window separating him from the studio recalls the common expression 'behind the glass', used by sound engineers and producers to differentiate themselves from those on the other side of the glass making acoustical sounds (usually musicians). Schaeffer's physical shift from recording room to sound booth from production to perception, from performing sounds to listening to them - coincides with the period where, as Brian Kane has shown, Schaeffer's formative ideas of musique concrète, reduced listening, and the sound object coalesced.

Once behind the glass, Schaeffer turned his attention towards developing his skills as an expert listener and in studio manipulation, and searching for ways to break the chain of signification with sound sources that had troubled him up to that time. Of several important developments in studio technique, the 'locked groove', a method of deliberately scratching a disc so that it would play a sound in a perpetual loop, is of special importance here. Schaeffer noticed that by listening to a looped recording of a train while composing Étude aux chemins de fer the sound seemed to lose its referentiality, such that Schaeffer's perception shifted to other purely sonic attributes of the sound. From this experiment, he concluded that the way to create musical syntax from concrète sounds was to break the chain of signification with the sound source (Schaeffer 2012: 13). This led to one of Schaeffer's most controversial concepts, 'reduced listening' (Emmerson 2007: 3). Reduced listening in the case of the 'locked groove' is similar to the cognitive effect of 'semantic satiation', a kind of auditory habituation effect where repeated exposure to a stimulus reduces sensitivity. Semantic satiation causes a shift in perception of the non-semantic attributes of speech sounds. As Sheila Black puts it: 'As repeated information becomes less available, more attentional resources can be diverted from stimuli with little information-value and directed toward new potentially informative stimuli' (Black 2003: 63).

On the evidence of Schaeffer's diaries alone, his decision to move 'behind the glass' was a pivotal moment in the development of musique concrète. But what informed this decision? The incomplete explanation written in his diary is every bit as tantalising as his statement about 'doing phenomenology without knowing it'. Schaeffer's education and professional vocation provide some interesting clues.

As an 'audio engineer by trade' (Holmes 2008: 49), it would have been hard for Schaeffer to remain unaware of the theories of sound fidelity established by the engineers associated with the BTL-sponsored research projects in sound reproduction. During the years that Schaeffer received his education and was professionally active, information and discoveries or techniques in electrical engineering were disseminated globally via conferences and the journals of national societies. Establishing internationally consistent standards and measurements also ensured close collaboration between scientific institutions in France, Germany, the United States and Britain (Neberker 2009: 351-3). Schaeffer was frequently required to travel abroad to conferences, and later in life remarked: 'I was an electroacoustic engineer working for the French radio, so I was led to study sound and what's called "high fidelity" in sound' (Hodgkinson 1987). Indeed, his disappointment at the transparency of the microphone in the passage quoted above suggests a more general frustration with the prevailing ideology of sound reproduction.

The BTL researchers even provided a precedent for acousmatic listening: the so-called 'ceno-orchestra' project, in which a live electrically amplified concert was staged in Philadelphia, then transmitted via custom designed trunk cables to Washington DC where an exclusive audience of invited critics, scientists, public figures and musical luminaries listened acousmatically through several banks of loudspeakers mounted on a stage (McGinn 1983: 57).

In summary, Schaeffer's pivotal move from the recording booth to the sound booth embodies a shift in focus from sound production to specialised listening that resonates with the concerns of the emergent class of professional sound engineers working at BLT in the years between the two world wars. In the following section I will elaborate the theoretical legacy of the phonographic 'Is it art?' moment and its influence on both Pierre Schaeffer and composers of the WSP. 


\section{THE LEGACY OF THEORIES OF SOUND FIDELITY}

Music occupied a special place in acoustical research journals of the 1920s and 1930s. Real-world examples of nascent psychoacoustic principles were often hashed out using musical jargon ; for example, Harvey Fletcher and W. A. Munson's use of musical dynamics as an empirical point of reference in their groundbreaking study of loudness perception (Fletcher and Munson 1933: 82). Perhaps not surprisingly, orchestral recording emerged as a kind of gold standard for sound reproduction against which all other methods were evaluated (Symes 2004: 7; Lastra 2000: 163-4). The scope of the literature surrounding research into sound reproduction was extremely broad; fidelity theories went far beyond describing the process of setting up a microphone and recording and reproducing sounds. Three texts will help to illustrate this point.

The first two examples show the careful construction of the sound engineer as specialist listener, removed from the area of sound production. First, H. D. Arnold's introduction to Harvey Fletcher's book Speech and Hearing: 'Our ears are only machines to translate air waves into a form suited to stimulate the auditory nerve; and as machines we may measure them in the same terms that apply to devices we ourselves construct' (Fletcher 1929: xi-xii). The late nineteenth century is full of such analogies between the human body and various types of machines (Rabinbach 1992); what is remarkable about this particular example is the emphasis on their interdependence. Skilled listening seems to require a connected system of ears and microphones that measure and calibrate each other in a phenomenological feedback loop. BTL engineer Frank B. Jewett described the acoustic phenomena that this system should hear as follows:

For the perfect pick-up, transmission and reproduction of orchestral music a system is needed, such that the sound reproduced in the ears of the listener is the same as that which would be produced in his ears if he were listening to the orchestra directly. In other words, the frequency, intensity and phase relations of the sound in each ear must be accurately reproduced in order best to convey the frequency and intensity range of the sounds and the spatial relations of the instruments. (Jewett 1933: 435)

The emphasis on these three properties of sound recalls the three planes of Schaeffer's 'complex note': dynamics, spectrum and tessitura (Schaeffer 2012: 196).

The final example is a report published in the Journal of the Acoustical Society of America in 1931 by the committee charged with formulating a set of standard terminology for use in the acoustical sciences (Firestone et al. 1931). This fascinating document gives an intriguing glimpse into the way that scientists and researchers conceptualised sound in the most general terms, and it probably deserves a study in its own right.
Overall the document expresses a desire to construct a robust multidisciplinary terminology that will be of use to scientists and musicians both, in communicating about any feature of sound or audition. Significantly, the document begins with two definitions of the word 'sound', the first describing a physical wave, and the second the 'sensation produced through the ear'; this splitting of the definition of sound into a physical phenomenon and its auditory perception prefigures the source/cause debate in post-Schaefferian discourse.

Taken together, these texts go far beyond the mandate of describing methods for the electrical reproduction of sound. They are an ambitious attempt to create an entire sonic worldview, one closely linked to highbrow classical music culture. In the following section I show how fidelity theories acted as a kind of ideological Trojan horse, carrying this sonic worldview over into the realm of electroacoustic music, most audibly via the theories of Pierre Schaeffer and latterly the WSP.

\section{FIDELITY THEORIES AS SONIC WORLDVIEWS}

In both Schaefferian and soundscape theory, one sees an attempt to forge a comprehensive system for identifying and categorising any type of sound event. This creates conflicts in theory and has provoked possibly unnecessary disputes. For example, Michel Chion has rightly pointed out that Schaeffer's conception of causality is overly simplistic in that it assumes a single, unique physical world source for each object. Chion elaborates his point by describing the sound of a felt pen with which he is writing his text, noting that rather than a single source there is a chain of causality which includes the pen, the texture of the paper, the implied presence of the author and the inscription of his physical gestures into the sound as he writes. He adds that were the sound to be recorded, then each part of the electroacoustic medium including microphones, speakers and room acoustics would also have to be accounted for (Chion 2012: 49).

But Chion and Schaeffer are talking about very different instances of sound production. Schaeffer's sound objects were conceived, performed and articulated through recording with particular sonic objectives in mind. In the case of Schaeffer's studio, tightly controlled recording conditions helped to create a relatively coherent singular cause for his sound objects. Chion's chain of causality certainly exists, but is less relevant in this case because these sounds are fabricated with a more one-dimensional notion of causality in mind. In a sense, Chion and Schaeffer are both right: their notions of what sound is and how it should function for a particular auditor in a given situation are simply different because those situations are different. 
Tensions also exist between what Schaeffer's theories, and those of the WSP, attempt to achieve generally, and how individual composers or compositional schools implement them in practice. This is in part a result of lofty ambitions. Brian Kane notes that the TOM is 'extraordinarily broad in scope' (Kane 2014: 17), and Schaeffer himself states that the theory of sound objects is intended to apply to the whole universe of sounds already available, or capable of being made' (Chion 1983: [38]). In practice however, sound objects should 'lend themselves easily to reduced listening, therefore not be too anecdotal or too loaded with meaning or emotion' (Chion 1983: [97], emphasis in original).

Similarly, soundscape theory articulates a vision for describing and potentially designing every element of a soundscape, 'traditional' or electroacoustic (Truax 1984), yet the subject of which sounds and modes of presentation are more appropriate to soundscape as a compositional genre are the source of some disagreement. This is most evident when a composer chooses the 'wrong' sounds ; for example, Hildegard Westerkamp's criticism of composer Michael Rüsenberg's choice of a noisy urban environment as the basis of a soundscape composition (Westerkamp 2002: 54). At moments such as these one is tempted to agree with Tim Ingold that the term 'soundscape' has perhaps outlived its usefulness. According to Stefan Helmreich, Ingold argues that soundscape theory 'objectifies sound rather than treating it as experiential' (Helmreich 2010). Instead, I would argue if soundscape is recognised as a particular musical culture informed by an environmentalist ideology, rather than a comprehensive taxonomy that should handle any and all instances of environmental sound - urban, pastoral, or otherwise - then it will cause fewer theoretical headaches.

Composers from the post-Schaefferian and soundscape groups often repeat the familiar refrain that recording opens up the possibility of using all and any real-world/ environmental sound as material for composition (Truax 1996: 49); yet when it comes time to make music, we should consider that for a particular composer, all sounds are not created equally.

\section{CONCLUSION: IN SEARCH OF THE PRO- PHONOGRAPHIC}

Fidelity theories - the 'inaudible visitors' of the title of this article - entered Schaefferian and soundscape music uninvited, and had the effect of shifting theoretical and practical emphasis away from sound production towards specialised listening and studio techniques. At the same time, fidelity theories demand a sonic worldview, a retroactive definition of the 'original' sound world they purport to reproduce. Though it is well beyond the scope of this article to prove conclusively, my hunch is that these shifts have created some blind spots in electroacoustic music theory in general.

For example, characterising listening as a form of auditory perception as the BTL scientists did excludes many types of listening and listeners, perhaps most obviously embodied approaches found in deaf musical culture or Pauline Oliveros's concept of 'deep listening', or forms of internal listening such as the practice of 'audiation' in traditional composition (Gordon 2002). Seth Kim-Cohen's call for a non-cochlear approach to sound art has triggered a conversation addressing many of these issues (Kim-Cohen 2009; Ciglar and Marolt 2012), so I will focus here on the corollary aspect of real-world sound fabrication.

Schaeffer's move from the recording booth to the sound booth resulted in a shift towards skilled listening and a complementary de-emphasis of the production, performance, or fabrication of acoustical sound events. A similar trend is evident in some accounts of soundscape ; for example, Barry Truax's brief history of soundscape subgenres at Simon Fraser University (Truax 2002). A large part of Truax's paper focuses on advanced sound manipulation and montage techniques that evolved in tandem with a desire for using more abstract materials and spatial narratives. He only briefly mentions recording technique, which is surprising considering soundscape composition's heavy reliance on field recording.

Both Schaefferian and soundscape theorists too often focus on what happens in the studio, after the sound or material gathering process (whether that takes place in the 'real' sonic world or not). This observation probably seems self-evident and even natural for many composers of electroacoustic music, for whom the computer and the studio, and only in some cases the microphone, are the primary tools of their craft (consider the number of publications titled with some variant of the phrase 'The studio as instrument'). Yet approaching sonic materials as 'found sounds' and focusing on studio craft as the locus of compositional activity gives an incomplete picture of electroacoustic composition. Denis Smalley's work Base Metals (2000) is a case in point.

Smalley sourced the sounds used in this composition from Derek Shiel's metal sound sculptures (Young 2010: 31). Shiel also performs his sculptures in concert settings, sometimes in ensembles with other instrumentalists. There are at least two extremely thorough analyses of Base Metals published to date (Lotis 2003; Hirst 2011), both of which are undeniably valuable in terms of helping listeners come to grips with the structuring and manipulation of sound materials in the composition. They also raise many other important issues, including the complex relationship of Smalley's analytical methodology to his own music. However, neither mention Shiel's contribution to Base Metals, and do not seem to consider the fabrication of the sounds used in the composition as part of the compositional process. Analytical 
approaches like these place Shiel's sculptures in the past tense, missing other potentially revealing lines of inquiry. For example, Smalley describes how he collected these materials over a long period of time; how did he interact with Shiel during this period, and what if any mutual influence exists in the work of these two artists? What effect did Shiel's existing performance practice have on the selection of sounds, objects and performing techniques used in Base Metals? Who performed the samples for the composition?

Interestingly, many of the artists most recognisably associated with creating new sounds from physical objects did so without phonographic intervention; for example, the Intonarumori of the Italian Futurists, Harry Partch's instruments, Annea Lockwood's Piano Transplants series and the sounding sculptures of Len Lye. Some composers of instrumental concert music could also be mentioned in this category: Helmut Lachenmann's Musique concrète instrumentale adapts concrète principles to instrumental composition in order to draw new timbres and textures from traditional ensembles (Craenen 2014: 84), perhaps suggesting a missed opportunity for electroacoustic music.

Phonographic artistry was not always a primarily studio-oriented activity. Examples of mixed performativephonographic practices, where sounds are performed specifically with some kind of phonographic mediation in mind, were much more common in the era of mechanical recording before phonography's 'Is it art?' moment. Phonograph historian Patrick Feaster has documented these approaches, or techniques of 'phonomanipulation' as he calls them (Feaster 2011). Composers Paul Hindemith and Ernst Toch, working in 1930, made similar experiments where they composed and recorded musical fragments in anticipation of phonographic transposition, speed shifting and montage (Holmes 2008: 43-4). I disagree with Thom Holmes that their work constitutes 'proto-turntablism', since turntablists usually work with found materials, whereas Toch and Hindemith composed music to be recorded in anticipation of specific phonographic transformations, making them unique in the post-Edison era. The entire realm of recorded popular music could also be considered a practice of conceiving, performing and manipulating sounds in anticipation of phonographic mediation.

Recall Schaeffer's intriguing sounding spring/resonator instrument described previously: while for Schaeffer the results were 'profoundly monotonous' (Schaeffer 2012: 6), the work of contemporary sound sculptor Zimoun demonstrates that approaches exactly like this can produce work that is anything but (Collins, Schedel and Wilson: 2013: 159). There is an opportunity here to find new ways of connecting innovative performance practices involving physical objects and phonographic mediation. Before this can happen, a more adaptable and contextdependent theoretical approach to sound reproduction is required.
Where might such a theoretical reconsideration begin? To return to the comparisons with visual media introduced at the beginning of this article: when we look at photographs or watch movies, our notions of reality or truth are conditioned by our knowledge of various cultures of mediation; our interpretation of images changes depending on whether they appear in a narrative film, documentary, or news footage (Lastra 2000: 77-8). Fidelity theories, in contrast, encourage us to listen to mediated sonic events as if they were unmediated; absent from most discussions of sound reproduction is a consideration of the "prophonographic' (Altman 1992: 258 n12), a consideration of how the conditions of recording such as acoustic ambience, performance practice, composition and recording technique are deliberately manipulated in the service of a specific sonic outcome.

Of course this is not to say that these issues go completely unaddressed in some form in discussions of electroacoustic music. 'Soundwalk', a subgenre of soundscape composition, offers a good example of a more flexible approach to the issue of how phonographic artistry plays out before sounds reach the studio. Composer and Soundwalk artist Hildegard Westerkamp, unlike the BTL engineers of the 'Is it art?' moment, does not assume that she can be an impartial auditor of a soundscape without having any effect on it (Westerkamp 2002). On the contrary, Soundwalk artists acknowledge their own sounding; they have an audible presence in the soundscape, and embrace the freedom to explore it from the standpoint of their own cultural and artistic identity (McCartney 2014: 213).

But in general, theories of sound reproduction whose job it is to describe the way in which realworld sounds are conceived, performed and mediated and find their way into the studios of electroacoustic music composers, sound artists and other electronic musicians of various stripes - are based on an overly generalised and, for creative purposes, largely irrelevant model of sound representation inherited from an increasingly remote musical culture. For Pierre Schaeffer, and perhaps for others too, fidelity theories seemed to render the pro-phonographic "profoundly monotonous'; it need not be, and searching for more imaginative alternatives could hold new possibilities for composers and theorists alike.

\section{REFERENCES}

Abel, R. 1988. French Film Theory and Criticism: A History/ Anthology, 1907-1939. Princeton, NJ: Princeton University Press.

Altman, R. (ed.) 1992. Sound Theory, Sound Practice. New York: Routledge.

Black, S. R. 2003. Review of Semantic Satiation. In S. P. Shohov (ed.) Advances in Psychology Research, volume 26. New York: Nova Biomedical. 
Bordwell, D. 1999. On the History of Film Style. Cambridge, MA: Harvard University Press.

Burns, R. W. 1999. The Life and Times of Alan Dower Blumlein. London: Institution of Electrical Engineers.

Carroll, N. 2008. The Philosophy of Motion Pictures. Malden, MA: Blackwell.

Chion, M. 1983. Guides des Objets Sonores: Pierre Schaeffer et la recherche musicale. Trans. Christine North and John Dack Buchet/Chastel: Institut national de la communication audiovisuelle.

Chion, M. 2012. The Three Listening Modes. In J. Sterne (ed.) The Sound Studies Reader. London: Routledge.

Ciglar, M. and Marolt, M. 2012. ICMC2012, Non-cochlear sound. Proceedings of the International Computer Music Conference, 9-14 September 2012, Ljubljana, Slovenia. San Francisco: International Computer Music Association.

Collins, N., Schedel, M. and Wilson, S. 2013. Electronic Music. Cambridge: Cambridge University Press.

Craenen, P. 2014. Composing Under the Skin: The MusicMaking body at the Composer's Desk. Leuven: Leuven University Press.

Dack, J. 1994. Pierre Schaeffer and the Significance of Radiophonic Art. Contemporary Music Review 102: 3-11.

Demers, J. 2010. Listening through the Noise: The Aesthetics of Experimental Electronic Music. New York: Oxford University Press.

Emmerson, S. 2007. Living Electronic Music. Burlington, VT: Ashgate.

Feaster, P. 2011. A Compass of Extraordinary Range: The Forgotten Origins of Phonomanipulation. ARSC Journal 42(2): 163-203.

Firestone, F. A. et al. 1931. Report of committee on acoustical standardization. Journal of the Acoustical Society of America 2(3): 311-24.

Fletcher, H. 1929. Speech and Hearing. New York: D. Van Nostrand Co.

Fletcher, H. and Munson, W. A. 1933. Loudness, its Definition, Measurement and Calculation. Journal of the Acoustical Society of America 5: 82-108.

Giblett, J. 2012. Photography and Landscape. Bristol: Gardners Books.

Gordon, E. 2002. Preparatory Audiation, Audiation, and Music Learning Theory: A Handbook of a Comprehensive Music Learning Sequence. Chicago: GIA Publications.

Harvith, J. and Edwards Harvith, S. (eds.) 1987. Edison, Musicians and the Phonograph: A Century in Retrospect. New York: Greenwood Press.

Helmreich, S. 2010. Listening Against Soundscapes. Anthropology News December: 10.

Hirst, D. 2011. From Sound Shapes to Space-Form: Investigating the Relationships between Smalley's Writings and Works. Organised Sound 16(1): 42-53.

Hodgkinson, T. 1987. Interview with Pierre Schaeffer. Recommended Records Quarterly 2(1): 3-10.

Holmes, T. 2008. Electronic and Experimental Music, 3rd edn. New York: Routledge.

Janson, H. W. and Janson, A. F. 2003. History of Art: The Western Tradition. Upper Saddle River, NJ: PrenticeHall.

Jewett, F. B. 1933. Perfect Quality and Auditory Perspective in the Transmission and Reproduction of Music. Science 77: $435-40$.
Kahn, D. 1990. Audio Art in the Deaf Century. In D. Lander and M. Lexier (eds.) Sound by Artists. Toronto: Art Metropole.

Kane, B. 2014. Sound Unseen: Acousmatic Sound in Theory and Practice. New York: Oxford University Press.

Kim-Cohen, S. 2009. In the Blink of an Ear: Toward a Non-Cochlear Sonic Art. New York: Continuum.

Landy, L. 2007. Understanding the Art of Sound Organization. Cambridge, MA: MIT Press.

Lastra, J. 2000. Sound Technology and the American Cinema: Perception, Representation, Modernity. New York: Columbia University Press.

Latour, B. 1987. Science in Action: How to Follow Scientists and Engineers through Society. Cambridge, MA: Harvard University Press.

Lotis, T. 2003. The Creation and Projection of Ambiophonic and Geometrical Sonic Spaces with Reference to Denis Smalley's Base Metals. Organised Sound 8(3): 257-67.

Marien, M. W. 2006. Photography: A Cultural History. London: King.

Maxfield, J. P. 1932. Acoustic Pick-up for Philadelphia Orchestra Broadcasts. Journal of the Acoustical Society of America 4: 122-28.

McCartney, A. 2014. Soundwalking: Creating Moving Environmental Sound Narratives. In Gopinath, Sumanth and Jason Stanyek (eds.) The Oxford Handbook of Mobile Music Studies volume 2. New York: Oxford University Press.

McGinn, R. 1983. Stokowski and the Bell Telephone Laboratories: Collaboration in the Development of High-Fidelity Sound Reproduction. Technology and Culture 24(1).

Monaco, P. 2010. A History of American Movies: A Film-byFilm Look at the Art, Craft, and Business of Cinema. Lanham, MD: Scarecrow Press.

Morton, D. 2000. Off the Record: The Technology and Culture of Sound Recording in America. New Brunswick, NJ: Rutgers University Press.

Neberker, F. 2009. Dawn of the Electronic Age: Electrical Technologies in the Shaping of the Modern World, 1914 to 1945. Hoboken, NJ: Wiley.

Ogborn, D. 2008. Interview with Robert Normandeau. eContact! Online Journal for Electroacoustic Practices 11(2). http://econtact.ca/11_2/normandeauro_ogborn.html (accessed 2 September 2016).

Rabinbach, A. 1992. The Human Motor: Energy, Fatigue, and the Origins of Modernity. Berkeley: University of California Press.

Randel, D. M. 2003. The Harvard Dictionary of Music Cambridge, MA: Belknap Press of Harvard University Press.

Read, O. and Welch, W. L. 1959. From Tin Foil to Stereo. Indianapolis: Bobbs-Merrill Co.

Sandler, M. W. 2002. Photography: An Illustrated History. Oxford: Oxford University Press.

Schafer, R. M. 1977. The Tuning of the World. New York: A. A. Knopf.

Schaeffer, P. 2012. In Search of a Concrète Music. Trans. Christine North and John Dack. Berkeley: University of California Press.

Sterne, J. 2003. The Audible Past: Cultural Origins of Sound Reproduction. Durham and London: Duke University Press. 
Symes, C. 2004. Setting the Record Straight: A Material History of Classical Recording. Middletown, CT: Wesleyan University Press.

Truax, B. 1984. Acoustic Communication. Norwood, NJ: Ablex.

Truax, B. 1996. Soundscape, Acoustic Communication and Environmental Sound Composition. Contemporary Music Review 15(1): 49-65.

Truax, B. 2002. Genres and techniques of soundscape composition as developed at Simon Fraser University. Organised Sound 7(1): 5-14.

Van Gelder, H. and Westgeest, H. 2011. Photography Theory in Historical Perspective. Malden, MA: Wiley-Blackwell.

Wallis, C. 1936. The Future of Romanticism. The Gramophone, March, 10.

Westerkamp, H. 2002. Linking Soundscape Composition and Acoustic Ecology. Organised Sound 7(1): 51-6.
Willie, E. J. 1993. Primary Compositional Characteristics in the Instrumental Music of Paul Lansky as Demonstrated in Hop. Denton, TX: UNT Digital Library. http://digital. library.unt.edu/ark:/67531/metadc33214/ (accessed 14 September 2016).

Worby, R. 2000. Cacophony. In S. Emmerson (ed.) Music, Electronic Media and Culture. New York: Routledge.

Young, J. 2010. Annotated Catalogue of Denis Smalley's Opus. In Évelyne Gayou (ed.) Denis Smalley: Polychrome Portraits. Paris: GRM de l'Ina.

\section{DISCOGRAPHY}

WSP. 1997. The Vancouver Soundscape 1973/Soundscape Vancouver 1996. Vancouver: Cambridge Street Publishing, CSR-2CD 9701. 